\title{
The implementation of the Traffic Management Act in England: the role of technology
}

\author{
P. E. Canning ${ }^{1,2}$, E. E. Hellawell ${ }^{2}$, S. J. Hughes ${ }^{2}$, C. J. Fairhead ${ }^{1}$ \\ \& B. C. M. Gatersleben ${ }^{3}$ \\ ${ }^{1}$ Surrey County Council, Intelligent Transport Systems, Surrey, UK \\ ${ }^{2}$ Department of Civil Engineering, University of Surrey, $U K$ \\ ${ }^{3}$ Department of Psychology, University of Surrey, UK
}

\begin{abstract}
For several years, UK transport policy has discouraged the construction of additional road space in order to meet the rising demand for road travel. Increasingly, Local Traffic Authorities (LTAs) in England instead look towards technology and Intelligent Transport Systems (ITS) for maximising the efficiency with which they use their road networks. The aim of this paper is twofold. Firstly, it provides a perspective on how English LTAs are using and planning to use ITS. Primarily, the recent UK Traffic Management Act influences these new strategies including the types of technology they are choosing. Findings are presented from some research carried out with a variety of English LTAs examining their use of and opinions concerning technology and ITS.

A case study is then provided on how one English LTA (Surrey County Council) is deploying ITS to help meet its new obligations. Conclusions are then drawn on the efficacy of setting central policy to influence LTAs in this manner. Keywords: Intelligent Transport Systems, Traffic Management Act, road space utilisation.
\end{abstract}




\section{Introduction and background to the Traffic Management Act}

In the $20^{\text {th }}$ century, car ownership grew from being the preserve of very few to a global fleet of over 460 million vehicles by the turn of the millennium (Moriarty and Honnery [1]). The UK has been no exception to this trend. In the last 20 years in particular, UK road traffic has grown significantly. In 2004, 502 billion vehicle kilometres were travelled on British roads an increase of $81 \%$ since the 1980s (Department for Transport \& Office for National Statistics [2]).

Until relatively recently, the predominate view of how to deal with this demand was that additional road space should be created - so called 'predict and provide'. This is now largely a redundant concept in most developed nations, with the acceptance that other, more sustainable measures are required to deal with the increase in demand for travel. Hence, instead of building new roads, UK transport policy is now directed towards the better management of existing infrastructure and users (Canning et al [3]). This policy is reflected through the introduction of new legislation in England - The 2004 Traffic Management Act.

The 2004 Traffic Management Act has delegated additional powers and responsibilities to Local Traffic Authorities (LTAs) in England with regards to the management of their road networks. In particular, they are now under a specific Network Management Duty to manage and deal with the causes of congestion and delays on their network. They are also required to appoint a named individual to the position of 'Traffic Manager' who has principal responsibility for ensuring that the LTA is discharging its responsibilities under the Act (Department for Transport [4]).

This paper investigates how LTAs are implementing the 2004 Traffic Management Act. It focuses on the use of technology and Intelligent Transport Systems (ITS) in meeting the new Network Management Duty and achieving optimal operational use of the road network. The objective was to determine if there was a difference in how ITS were being implemented amongst different types of LTA. This initial investigation into the use of Intelligent Transport Systems as a tool to manage road networks forms part of a wider programme aimed at evaluating sustainable transport systems for the future. In this paper, results from an electronic survey and follow-up interviews are discussed to ascertain how ITS are currently used by different types of English LTA and the perceived future potential for them. A case study is then reported to demonstrate the ways in which one proactive English LTA is implementing ITS.

\section{Methodology}

Each of the 150 English LTAs is required to appoint a Traffic Manager. These LTAs represent a wide variety of areas differing in size, geography and Local Government structure.

An electronic survey was designed and sent via email to the 150 Traffic Managers. The survey included four discrete themes, comprising: 
- The use of technology for implementing the Traffic Management Act

- The traffic managers opinions on different forms of congestion charging - something increasingly considered as a form of demand management.

- The use of "permit systems" for road and street works.

- How they established the functional role of the new traffic manager.

This paper focuses on the section of this survey concerning the use of technology for implementing the Traffic Management Act. This section asked questions specifically about the use of Urban Traffic Management \& Control (UTMC) within the LTA and the potential benefits that might be realised. UTMC is the principal mechanism used by UK LTAs for integrating ITS and delivering better traveller information.

A total of 61 responses were received, which equated to a response rate of $41 \%$. These responses represented a wide range of different LTA types, as illustrated in table 1.

Table 1: $\quad$ Types of LTA that responded to the survey.

\begin{tabular}{|l|c|}
\hline LTA type & $\begin{array}{c}\text { Number of } \\
\text { responses }\end{array}$ \\
\hline County Council & 22 \\
\hline Unitary Authority & 16 \\
\hline Metropolitan Borough & 8 \\
\hline London Borough & 12 \\
\hline City Council & 3 \\
\hline Total & 61 \\
\hline
\end{tabular}

Building upon the responses from the original survey, additional questions were then designed for the purposes of conducting telephone interviews with a number of Traffic Managers. 11 Traffic Managers were selected for the interview phase of the project. This was undertaken to provide more focussed information on some of the relevant issues that became apparent from the first survey. The selection process ensured a good geographical spread of authorities, including one from each of the eight English regions (for the purposes of regional governance, the $\mathrm{UK}$ is divided into 8 English regions plus Wales, Scotland and Northern Ireland). Two of the authorities were also chosen because they had been accepted for funding from the UK Government's Transport Innovation Fund (TIF). The TIF funds innovative new transport projects concerning demand management, so acceptance for such funds is an indication that a LTA is proactive in its approach to transport. The types of authority selected for the interview phase are detailed in table 2 .

Following an analysis of the data concerning the type of authority and the information provided by the respondent on the nature of the area (e.g. predominantly rural / predominantly urban) each set of responses was separated into one of three categories. These categories were: 
Table 2: $\quad$ Types of LTA selected for the second stage interviews.

\begin{tabular}{|l|c|}
\hline Type of authority & Number interviewed \\
\hline Predominantly rural County Council & 3 \\
\hline London Boroughs & 2 \\
\hline Metropolitan Borough Councils & 2 \\
\hline Unitary Authority & 1 \\
\hline City Council & 2 \\
\hline Urbanised County Council & 1 \\
\hline Total & 11 \\
\hline
\end{tabular}

- London Borough.

- Predominantly urban LTA

- Predominantly rural LTA.

These three categories represent three distinct types of LTA within England. The London Borough category was chosen specifically because these types of LTA share their highways responsibilities with Transport for London (TfL), which has responsibility for some of the more strategic functions of transportation within the greater London conurbation. Urban and rural were chosen because of the relative population densities and traffic pressures present in those areas.

\section{Results and discussions}

Based on the survey results and principally on how the respondents described their own areas, the 61 survey results were subdivided into three categories outlined in the methodology. Table 3 shows the number of LTAs in each category.

Table 3: $\quad$ The types of LTA responding to the survey.

\begin{tabular}{|l|c|}
\hline Type of authority & Number of responses \\
\hline London Borough & 12 \\
\hline Predominantly Rural LTA & 22 \\
\hline Predominantly Urban LTA & 27 \\
\hline Total & 61 \\
\hline
\end{tabular}

Section 3.1 includes both the results for the whole sample along with a comparative breakdown for each subcategory of LTA.

\subsection{Use of UTMC and other technology for meeting the Network Management Duty}

Technology is one of the ways suggested by the Traffic Management Act for meeting the Network Management Duty. The first question in this section of the survey was to ascertain the extent to which LTA's already use UTMC 
technologies in their area. Hence, the survey asked whether LTAs were using technologies developed as part of the Urban Traffic and Management Control project (UTMC).

Table 4: The current usage of UTMC technologies within a subset of UK LTAs.

\begin{tabular}{|l|c|c|c|c|}
\hline & $\begin{array}{c}\text { All } \\
(\%)\end{array}$ & $\begin{array}{c}\text { London } \\
\text { Boroughs }(\boldsymbol{\%})\end{array}$ & $\begin{array}{c}\text { Urban LTAs } \\
\mathbf{( \% )}\end{array}$ & $\begin{array}{c}\text { Rural LTAs } \\
\mathbf{( \% )}\end{array}$ \\
\hline Currently Using & 43.1 & 20.0 & 54.2 & 40.9 \\
\hline Planned use in the future & 36.2 & 30.0 & 29.2 & 45.5 \\
\hline No plans at present & 20.7 & 50.0 & 16.7 & 13.6 \\
\hline
\end{tabular}

$43 \%$ of those LTAs that answered the survey were currently using some form of UTMC technology with an additional 36\% having plans to use it in the future. The interest of the London Boroughs in UTMC was smaller than for other types of LTA. This could be anticipated given the nature of the technology and the Local Government structure in London whereby responsibilities are split between the boroughs and TfL - with TfL holding responsibility for more strategic functions such as the operation of traffic signals. A greater number of urban LTAs were presently using UTMC compared with rural LTAs, although a large number of rural LTAs $(45.5 \%)$ planned to use it in the future. This statistic probably relates to current traffic pressures in those areas compared with perceived future growth of traffic in more rural areas where car dependency is higher.

Table 5: How LTAs rate the potential benefits of UTMC for improving travel within their areas.

\begin{tabular}{|l|c|c|c|c|}
\hline & $\begin{array}{c}\text { All } \\
(\%)\end{array}$ & $\begin{array}{c}\text { London Boroughs } \\
(\%)\end{array}$ & $\begin{array}{c}\text { Urban LTAs } \\
(\%)\end{array}$ & $\begin{array}{c}\text { Rural LTAs } \\
(\%)\end{array}$ \\
\hline Very Promising & 24.1 & 30.0 & 34.6 & 9.1 \\
\hline Promising & 65.5 & 60.0 & 57.7 & 77.3 \\
\hline Not Promising & 8.6 & 10.0 & 7.7 & 9.1 \\
\hline Not Promising at all & 1.7 & 0.0 & 0.0 & 4.5 \\
\hline
\end{tabular}

Table 5 addresses the issue of perceived potential for the use of UTMC within the relevant LTA. Significantly more urbanised LTAs saw UTMC as "very promising' compared to rural LTAs, although 77\% of rural LTAs saw UTMC as 'promising'. The higher number of urban LTAs considering UTMC as very promising may represent the higher technological penetration of ITS within urban LTAs at present compared to other LTA types. In general though, the survey showed a positive perception on the potential benefits of UTMC across all LTA types. 
The follow up interviews supplied more detail on how traffic managers perceived the use of UTMC and other ITS'. Whilst 9 out of the 11 interviewees were broadly positive about the concept of UTMC and other technologies, there was some degree of uncertainty over the tangible benefits that could be realised from implementation. This was particularly noticeable amongst rural LTAs who expressed concerns that:

- $\quad$ Financial costs outweighed potential benefits.

- Technologies available at present were not always suitable for their LTA.

- The new responsibilities placed upon them were potentially burdensome rather than beneficial - especially if the technological route became an enforced choice.

This may explain why such a high proportion considered it as 'promising' as opposed to 'very promising'. There was a general agreement with the principal of providing better information to the traveller (another theme of the Traffic Management Act) - amongst all types of LTA. One urban LTA also expressed some uncertainty over how the new technologies being implemented might best be used. Figure 1 summarises some of the comments received.

"We need to give people a better picture of what's happening on the network"

\section{- $\quad$ Paraphrased by 7 of the Interviewees}

"We have quite a lot of technology, the trick will be to make the best use of it."

\section{- $\quad$ City Council}

"The dispersed nature of the area means there are few technological options that are practical for us"

- Rural County Council

Figure 1: Quotes from the Traffic Manager interviews concerning the use of technology.

The results from the questionnaire indicated that the majority of LTAs were in favour of using technology to better manage their road networks. Furthermore a significant percentage had already implemented the technology to some extent. The extent to which the technology is already being utilised can be seen in more detail by examining a specific LTA and its UTMC technology. Surrey County Council has been selected as a case study example of an English LTA that is 
implementing UTMC and other ITS'. Section 3.2 explains how this particular LTA has built upon previous work in light on new legislation in order to expand its use of UTMC and other ITS.

\subsection{Surrey County Council - a case study}

The response of Surrey County Council to this research was not uncommon from the responses received from the whole sample. Surrey County Council had already begun implementing ITS, principally as a response to growing traffic pressures and demand for better transportation provision from residents. Surrey was using UTMC and described it as 'very promising' in their survey response. The interview stage revealed how the new legislation had affected the speed at which the new ITS were being implemented and the funding made available by the LTA. The purpose of this section is to provide a case study example on how Surrey County Council, the relevant Local Traffic Authority for the County of Surrey in England is choosing to deploy its ITS. This is to provide a perspective on how new legislation has altered local policy with respect to the management of the local road network. This illustrates how the legislation in question has been able to positively influence the use of ITS amongst smaller units of government.

The County of Surrey lies immediately to the south of Greater London and has a population of just over 1 million. Surrey County Council is responsible for the maintenance and operation of $5316 \mathrm{Km}$ of roads in Surrey (in the UK, motorways and trunk roads are the responsibility of a separate national body, the Highways Agency). Surrey has a strong economy and a generally prosperous population, leading to high levels of car ownership and use. Average daily flows on Surrey's principal 'A roads', for example, are twice that of the UK average and car availability per person is $59 \%$ above the national average (The Surrey Local Transport Plan [5]). Given the already high burdens upon the road network and little prospect of significant expansion, Surrey County Council are keen to utilise ITS' and technologies as a way of improving the operational efficiency of their road network.

A dedicated Network Management and Information Centre (NMIC) was established in 2003 in order to provide a dedicated location for the development and exploitation of ITS for use on the Surrey road network. In order to address some of the issues raised by the high traffic flows, Surrey County Council has begun implementing a variety of ITS. Some of these were started prior to the implementation of the Traffic Management Act whilst others have been advanced more quickly as a result of the new Network Management Duty. Since the new legislation, however, the NMIC has taken a much stronger role within the LTA's policy framework. Funding for ITS has increased significantly in order for the new obligations to be met.

ITS being utilised and implemented by Surrey County Council include:

- Real Time passenger Information for buses in Surrey to make them a more attractive alternative to the car. 
- Car park guidance systems in four town centres to make it easier for drivers to find a free space without repeatedly circling car parks that are full.

- $\quad$ Roadside Visual Message Signs (VMS) to give out traveller information on prevailing road conditions - implemented directly as part of the new Network Management Duty.

- Dedicated access to other local CCTV providers so as to be able to identify the location of accidents and other disruptions on the highway.

A UTMC common database has also been purchased in order to integrate the various ITS available to Surrey County Council and better facilitate strategy creation. Figure 2 shows a schematic overview of the Intelligent Transport Systems operating within the Surrey County Council NMIC.

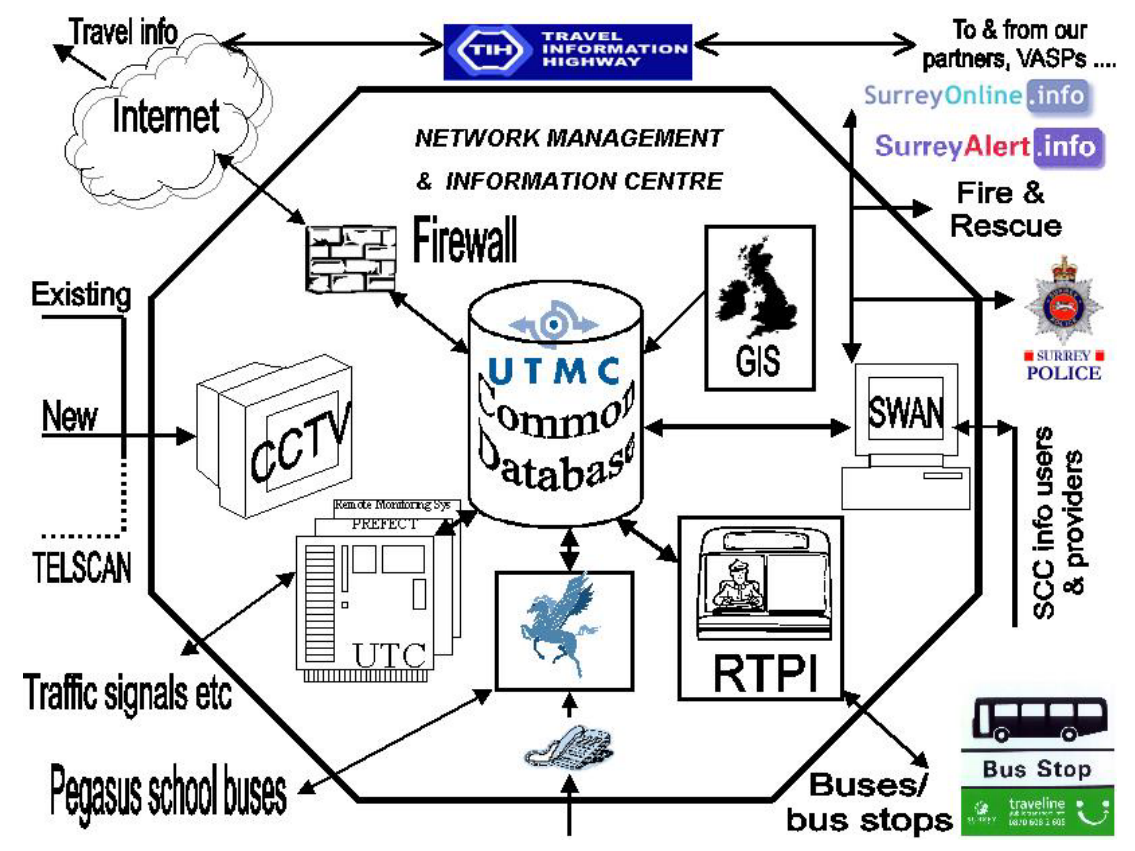

Figure 2: Schematic overview of Intelligent Transport Systems fed into the Surrey NMIC.

Whilst Surrey County Council had started to implement ITS prior to the new legislation, the new responsibilities placed upon it as a Local Traffic Authority under the Traffic Management Act have shortened the timetable for the introduction of various ITS within Surrey.

This is typical of a number of English LTAs (including Reading, Essex and Lancashire) where existing provision has been enhanced by the new legislation. This was substantiated by the telephone interviews conducted for this research. 
ITS have also become the centrepiece of the new 'network management plan' that Surrey County Council is obliged to produce as part of the new legislation.

Given the high levels of traffic currently using the local road network, ITS are an obvious choice for the best way to reduce the impact of these high traffic flow rates. The new legislation - obliging LTAs to demonstrate a proactive approach, makes it a higher priority within the political arena of a Local Authority where transportation must compete against other public services (such as social services and education) for funding.

\section{Conclusions}

A questionnaire was sent out to determine the extent to which UTMC and ITS were being used across LTAs in England. A number of LTAs, particularly those in urban areas were shown to be proactive in this area. London Boroughs and rural LTAs were less likely to be presently using UTMC. Of those not currently using it, most were considering its use in future. The interviews conducted confirmed that the new duties provided by the Traffic Management Act had made many LTAs more proactive about their attitude to UTMC and other ITS.

The potential benefits of UTMC and other ITS' are generally recognised across the country. This should be considered against the UK policy background of making better use of existing, finite road space as opposed to the construction of additional infrastructure. Setting Central policy in this way, that influences different types of LTA, is generally successful. It should be noted, however that whilst the new legislation has been a positive influence for most LTAs, there were some concerns that this may lead to funds being diverted from other important activities carried out by the authority, for example regeneration. An example has also been presented of a proactive English LTA and the measures they have taken to implement the new legislation and the types of ITS they are using in order to achieve this. The work set out in this paper is thus intended to have illustrated some of the benefits and pitfalls of encouraging ITS uptake from the English example.

\section{Acknowledgements}

The authors wish to thank all of those who completed the original survey and took part in the structured telephone interviews for their time and their comments. Robert Hudleston and Tim Brown from Surrey County Council are also acknowledged for their guidance and assistance.

The EPSRC and Surrey County Council are gratefully acknowledged for jointly funding this research.

\section{References}

[1] Moriarty P., Honnery D., (January 1999) Slower, smaller and lighter urban cars, Proceedings of the I MECH E Part D Journal of Automobile Engineering, Volume 213, Number 1, 12, pp. 19-26(8) 
390 Urban Transport XIII: Urban Transport and the Environment in the 21st Century

[2] Department for Transport \& Office for National Statistics, (February 2006) Transport Trends: 2005 Edition

[3] Canning P.E, Hughes S.J., Hellawell E.E., Speroni P.J., Eves D., Winnet M., Wood K., "Strategic management of urban road networks", Smart Moving Conference, Birmingham NEC, April 19 ${ }^{\text {th }} 2005$

[4] Department for Transport, (November 2004) Traffic Management Act 2004 - Network Management Duty Guidance

[5] Surrey County Council, The Surrey Local Transport Plan 2006/7-2010/11 